\title{
Preparasi Proses Trans-Esterifikasi Minyak Jelantah dengan menggunakan Microwave Oven
}

\author{
Satwiko, S.* \\ Jurusan Fisika, FMIPA, Universitas Negeri Jakarta \\ JL. Pemuda No. 10 Rawamangun, Jakarta 13220
}

Intisari

Esterifikasi dilakukan untuk mendapatkan biodiesel dari minyak jelantah, microwave oven digunakan sebagai pemanas dengan variasi konsentrasi methanol diperlukan sehingga akan didapat hasil yang diharapkan. Salah satu faktor berpengaruh adalah temperature pembuatan sehingga perlu dijaga agar tidak terlalu tinggi, dengan menggunakan metode ini waktu pembuatan dapat dipersingkat serta mendapatkan pemanasan merata dari gelombang micro yang diapplikasikan.

KATA KUNCI: minyak jelantah, methanol, microwave

\section{PENDAHULUAN}

Biodiesel adalah senyawa alkil ester yang diproduksi melalui proses alkoholisis (transesterifikasi) antara trigliserida dengan metanol atau etanol dengan bantuan katalis basa menjadi alkil ester dan gliserol; atau esterifikasi asam-asam lemak (bebas) dengan metanol atau etanol dengan bantuan katalis basa menjadi senyawa alkil ester dan air.

Proses transesterifikasi dan esterifikasi dapat digabungkan untuk mengolah bahan baku dengan kandungan asam lemak bebas sedang sampai tinggi seperti CPO low grade, maupun PFAD. Sebagai bahan baku biodiesel dapat digunakan antara lain minyak jarak, minyak sawit, minyak kelapa. Biodiesel mempunyai rantai karbon antara 12 sampai 20 serta mengandung oksigen. Adanya oksigen pada biodiesel membedakannya dengan petroleum diesel (solar) yang komponen utamanya hanya terdiri dari hidrokarbon. Jadi komposisi biodiesel dan petroleum diesel sangat berbeda. Biodiesel terdiri dari metil ester asam lemak nabati, sedangkan petroleum diesel adalah hidrokarbon.

Di samping biodiesel tidak mengandung sulfur dan senyawa bensen yang karsinogenik, sehingga biodiesel merupakan bahan bakar yang lebih bersih dan lebih mudah ditangani dibandingkan dengan petroleum diesel. Penggunaan biodiesel juga dapat mengurangi emisi karbon monoksida, hidrokarbon total, partikel, dan sulfur dioksida. Emisi nitrous oxide juga dapat dikurangi dengan penambahan konverter katalitik. Kelebihan lain dari segi lingkungan adalah tingkat toksisitasnya yang 10 kali lebih rendah dibandingkan dengan garam dapur dan tingkat biodegradabilitinya sama dengan glukosa, sehingga sangat cocok digunakan pada kegiatan di perairan untuk bahan bakar kapal/motor. Biodiesel tidak menambah efek rumah kaca seperti halnya petroleum diesel

\footnotetext{
*E-MAIL: sidopekso61@yahoo.com.au
}

karena karbon yang dihasilkan masuk dalam siklus karbon. Untuk penggunaan biodiesel pada dasarnya tidak perlu modifikasi pada mesin diesel, bahkan biodiesel mempunyai efek pembersihan terhadap tangki bahan bakar, injektor dan selang.

Biodiesel memiliki beberapa kelebihan dibanding bahan bakar diesel petroleum. Kelebihan tersebut antara lain :

1. Dihasilkan dari sumber daya energi terbarukan dan ketersediaan bahan bakunya terjamin

2. Cetane number tinggi (bilangan yang menunjukkan ukuran baik tidaknya kualitas solar berdasar sifat kecepatan bakar dalam ruang bakar mesin)

3. Viskositas tinggi sehingga mempunyai sifat pelumasan yang lebih baik daripada solar sehingga memperpanjang umur pakai mesin

4. Dapat diproduksi secara local

5. Mempunyai kandungan sulfur yang rendah

6. Menurunkan tingkat opasiti asap

7. Menurunkan emisi gas buang

8. Pencampuran biodiesel dengan petroleum diesel dapat meningkatkan bio degradibility petroleum diesel sampai $500 \%$.

Pemanasan dengan gelombang mikro mempunyai kelebihan yaitu pemanasan lebih merata karena bukan mentransfer panas dari luar tetapi membangkitkan panas dari dalam bahan tersebut. Pemanasannya juga dapat bersifat selektif artinya tergantung dari dielektrik properties bahan. Hal ini akan menghemat energi untuk pemanasan. 


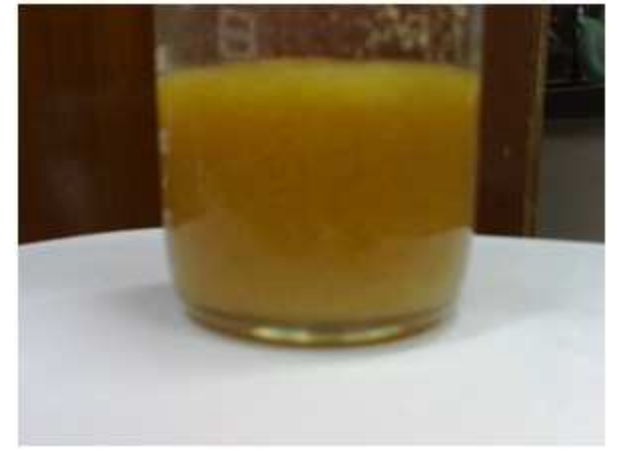

Gambar 1: Biodiesel sebelum proses reheating

\section{METODE PENELITIAN}

Bahan-bahan kimia yang digunakan dalam penelitian adalah minyak jelantah (nabati), $\mathrm{NaOH}$, dan methanol. Peralatan yang digunakan dalam penelitian ini meliputi: peralatan gelas seperti gelas kimia, gelas ukur, batang pengaduk, microwave, dan infrared thermometer.

\section{PROSEDUR}

\section{Proses trans-esterifikasi dengan microwave}

Minyak jelantah yang telah dipanaskan dengan microwave direaksikan dengan melarutan natrium metoksida. Pengemulsian kedua larutan tersebut dilakukan secara mekanik (mixing).

\section{Proses Reheating untuk trans-esterifikasi}

Minyak jelantah yang telah direaksikan dalam proses trans-esterifikasi dengan microwave dipanaskan kembali dengan microwave pada daya dan waktu yang sama.

\section{HASIL DAN PEMBAHASAN}

\section{Proses Trans-Esterifikasi Minyak Jelantah dengan Mikrowave}

Hasil proses trans-esterifikasi minyak jelantah yang dipanaskan terlebih dahulu dengan microwave lalu kemudian direaksikan dengan natrium metoksida. Data diperoleh disajikan pada Gambar 1.

Hasil proses trans-esterifikasi minyak jelantah kemudian dipanaskan kembali dengan daya dan waktu yang sama dihasilkan biodiesel telah terpisah dengan gliserin, seperti ditunjukkan dalam Gambar 2.

Pemisahan kedua bagian tersebut dapat dilakukan dengan penyaringan sederhana, dikarenakan fase gliserin dalam bentuk padatan, sehingga larutan metil ester (biodiesel) dapat mudah dipisahkan. Waktu pemisahan hanya memerlukan waktu kurang lebih 2 jam.

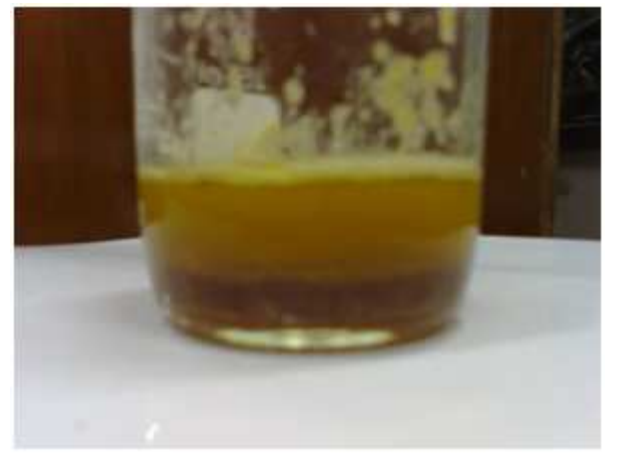

Gambar 2: Biodiesel setelah proses reheating

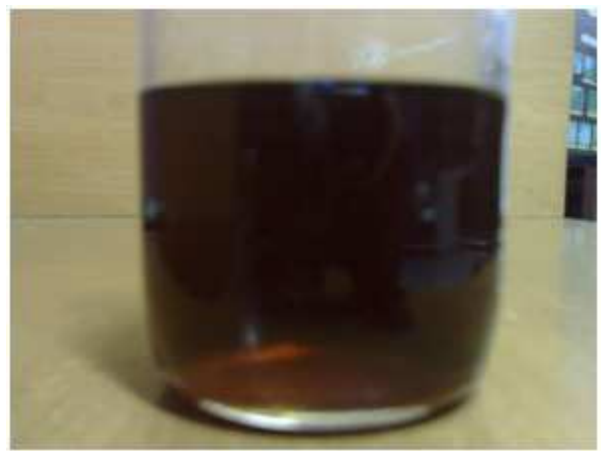

Gambar 3: Biodiesel setelah proses reheating dengan daya yang sama dan waktu 1,5 kali dari proses pertama

Pada saat pemanasan ulang apa bila terjadi temperature yang berlebihan akan mengakibatkan tidak terbentuknya biodiesel, disajikan dalam gambar 3 .

\section{SIMPULAN}

1. Pemanasan yang berlebihan mengakibatkan tidak terbentuknya biodiesel serta mengakibatkan tidak terlihatnya pemisahan antara dua lapisan, untuk itu perlunya di lakukan pemanasan dengan temperature yang tidak berlebihan.

2. Optimalisasi perlu dilakukan guna mendapatkan perbandingan yang sesuai dengan kecepatan pemanasan yang dilakukan pada system pemanasan ini, sehingga perlu dilakukan studi lanjutan. 
[1] Bagby, M.O, ASAE Paper No.87-1588. St Joseph, MI, pp.48 (1987).

[2] Dunn, P.D. and Jompakdee, W., Small Engine and Their Fuel, Sept., pp.44-49 (1993).

[3] Leung D.Y.C. and Guo Y., Fuel Processing Technology,Volume 87, Issue 10, October 2006, pp.883-890 (2006).

[4] Titipong Issariyakui, Mangesh G. Kulkarni, Ajay K. Dalai and Narendra N. Bakhshi, Fuel Processing Technology, Volume 88,
Issue 5, May 2007, pp.429-436 (2007)

[5] Ramadhas, Pembuatan Biodiesel dari Minyak Sawit dengan Esterifikasi Dua Tahap, Laporan Penelitian, Laboratorium Proses Kimia, Universitas Gajah Mada, Yogyakarta, 2005.

[6] Peterson, G.R. and Scarrah, W.P., J. Am. Oil Chem. Soc., 61 (10), p. 1593-1596 (1984). 